\title{
Peripheral blood mononuclear cell proliferation and cytokine production in sheep as affected by cortisol level and duration of stress
}

\author{
M. G. Ciliberti, M. Albenzio, C. Inghese, A. Santillo, R. Marino, A. Sevi, and M. Caroprese ${ }^{1}$ \\ Department of the Sciences of Agriculture, Food and Environment (SAFE), University of Foggia, Via Napoli, 25, 71122 Foggia, Italy
}

\section{ABSTRACT}

A large number of studies recognize glucocorticoids (Gc) as suppressors of inflammation; Gc exert an important role in coordinating the magnitude and duration of host immune responses. In the present in vitro investigation, we tested incremental levels of cortisol to verify the immunosuppressive or immunopermissive role of cortisol in sheep peripheral blood mononuclear cells (PBMC) after acute and chronic stress. Phytohemagglutinin (PHA)-stimulated PBMC were cultured for $24 \mathrm{~h}$ and $96 \mathrm{~h}$ at $37^{\circ} \mathrm{C}$ with $5 \%$ of $\mathrm{CO}_{2}$ and varying cortisol levels: $10 \mathrm{ng} / \mathrm{mL}$ (baseline), $100 \mathrm{ng} / \mathrm{mL}$ (physiological poststressor), and $1,000 \mathrm{ng} / \mathrm{mL}$ [hyperactivated hypothalamic-pituitary-adrenal (HPA) axis]. The cell-free supernatants were collected for determination of IL-6, IL-1 $\beta$, and IL-10 by ELISA, and the bromodeoxyuridine assay was performed on cells. Physiological cortisol concentration negatively affected the levels of IL-6 secreted by PBMC, resulting in increased cell proliferation after acute stress (24 h of incubation). However, physiological cortisol concentration exhibited a reduction in cell proliferation induced by increased levels of IL-6 secreted by PBMC during chronic stress (96 h of incubation). The cortisol concentration representing a hyperactivated HPA axis led to a reduction in cell proliferation after acute stress, which was probably induced by the elevated IL-10 production. Our results demonstrate that in sheep the effect of Gc on the immune system was related to the magnitude and the duration of stress. In particular, cortisol levels higher than physiological concentrations suppressed cell proliferation soon after acute stress. Instead, the physiological poststressor concentration of cortisol affected the immune responses in a bidirectional manner depending on the duration of the stressor.

Key words: sheep, cortisol level, immune responses, stress

Received July 1, 2016.

Accepted September 25, 2016.

${ }^{1}$ Corresponding author: mariangela.caroprese@unifg.it

\section{INTRODUCTION}

Stress is defined as a complex cascade of events, consisting of a stimulus (stressor) that causes a subsequent reaction in the brain (stress perception) and activates physiologic reactions (stress response) (Dhabhar and McEwen, 1997). The stress response connects the central nervous and the immune systems by activating the autonomic nervous system and the hypothalamicpituitary-adrenal (HPA) axis through the secretion of neuropeptides and hormones, including glucocorticoids (Gc). Munck et al. (1984) suggested that the role of Gc was to control the size of normal defense reactions to stress to avoid an excessive threat to homeostasis. Two contrasting actions of Gc on modulating immune responses have been defined; one action includes permissive and stimulating effects for activating defense mechanisms, and the other action is a suppressive action of stress reactions (Sapolsky et al., 2000). The permissive action induces enhancement of immune function to protect against stressors, whereas the suppressive action leads to adaptive suppression of immune responses to conserve energy for subsequent stressors (Sapolsky et al., 2000). However, very little information is available concerning the contrasting actions of Gc on immune responses in sheep after a stressor. Increased expression of receptors for inflammatory cytokines, such as IL-1 (Shieh et al., 1993), IL-2 (Wiegers et al., 1995), IL-4 (Paterson et al., 1994), IL-6 (Pietzko et al., 1993), IL-7 (Franchimont et al., 2002), and interferon- $\gamma$ (Strickland et al., 1986), as well as granulocyte-macrophage colonystimulating factor (Hawrylowicz et al., 1994) has been induced by Gc. In addition, Gc stimulate effector cell functions, including proliferative responses of $\mathrm{T}$ cells and macrophages (Yeager et al., 2009). A considerable body of evidence indicates that Gc can both enhance stress-induced defense mechanisms by stimulating proinflammatory cytokine secretion, as reported in sheep (Caroprese et al., 2010), and suppress innate inflammatory immune mediators such as the pro-inflammatory nuclear transcription factor $\kappa \mathrm{B}$ (De Bosscher et al., 2003).

One key factor that determines whether stress enhances or suppresses immune function is the duration 
of stress. A stressor lasting for a period of minutes to hours is defined as acute stress, whereas a stressor persisting for several hours a day for weeks or months is defined as chronic stress (Dhabhar, 2002). Acute stress has been hypothesized to be an adaptive psychophysiological mechanism that confers increased immune protection following wounding or infection. In contrast, chronic stress suppresses or dysregulates immune function (Dhabhar, 2014).

The aim of the present in vitro experiment was to study cellular responses to different magnitudes and durations of stress to verify the permissive or suppressive action of cortisol. The effects of cortisol on the proliferation and cytokine production of peripheral blood mononuclear cells (PBMC) from sheep were assessed.

\section{MATERIALS AND METHODS}

\section{Animals and Experimental Treatments}

Dairy sheep used in the study were allocated at Segezia research station of the Council for Research and Experimentation in Agriculture. Sixteen sheep were randomly chosen, and an in vitro experiment was performed, with incremental cortisol concentration and 2 different times of incubation after mitogen stimulation in a $2 \times 2$ factorial arrangement. All procedures were conducted according to the guidelines of the EU Directive 2010/63/EU (European Union, 2010) for the protection of animals used for experimental and other scientific purposes. The sheep were healthy, and they were carefully examined by veterinarians throughout the trial to exclude the presence of any signs of disease. The in vitro study was performed by the split-plot component involving the isolation of sheep PBMC and the evaluation of the cells' proliferative response and cytokine production after stimulation with the mitogen phytohemagglutinin (PHA) in the presence of 3 different concentrations of cortisol. Cortisol concentrations were chosen based on results from in vivo studies on sheep (Caroprese et al., 2010). The concentrations represented basal cortisol concentration $(10 \mathrm{ng} / \mathrm{mL})$, physiological poststressor concentration $(100 \mathrm{ng} / \mathrm{mL})$, and hyperactivated HPA axis concentration (1,000 ng/ $\mathrm{mL}$ ). Incubation times were $24 \mathrm{~h}$ to mimic an acute stressor and $96 \mathrm{~h}$ to mimic a chronic stressor.

\section{Isolation of PBMC}

Blood samples $(15 \mathrm{~mL})$ were collected in vacuum tubes from the jugular vein of sheep. Isolation of PBMC was performed by density gradient centrifugation according to Wattegedera et al. (2004). The separated $\mathrm{PBMC}$ were then resuspended at a final concentration of $2 \times 10^{5}$ cells $/ \mathrm{mL}$ in Iscove's modified Dulbecco's medium (Sigma Aldrich, Milan, Italy) supplemented with $10 \%$ fetal bovine serum (Sigma Aldrich) and 50 $\mu \mathrm{g} / \mathrm{mL}$ gentamicin (Euroclone, Milan, Italy).

\section{Lymphocyte Stimulation Assay and Cytokine Determination}

Lymphocyte proliferation assays were performed by adding $100 \mu \mathrm{L}$ of cell suspension into quadruplicate wells of 96-well U-bottomed plates. Peripheral blood mononuclear cells were either not activated or activated with $50 \mu \mathrm{L}$ of PHA (Sigma-Aldrich) at a final concentration of $10 \mu \mathrm{g} / \mathrm{mL}$. Sheep PBMC stimulated with PHA were treated with an incremental concentration of cortisol (Sigma-Aldrich; 10, 100, or 1,000 ng/ $\mathrm{mL}$ at final concentration). The plates were incubated at $37^{\circ} \mathrm{C}$ and $5 \% \mathrm{CO}_{2}$ in a humidified incubator for 24 or $96 \mathrm{~h}$. After incubation, plates were centrifuged at $1,000 \times g$ for $1 \mathrm{~min}$, and cell-free supernatants from each well were collected and stored at $-20^{\circ} \mathrm{C}$ until ELISA to measure cytokine production. After removal of the supernatant, cells were incubated with bromodeoxyuridine (Exalpha Biologicals Inc., Shirley, MA) to test lymphocyte cell proliferation. After $18 \mathrm{~h}$ of incubation, bromodeoxyuridine incorporation during DNA synthesis was measured by determining optical density with a titer-ELISA spectrophotometer (PowerWave XS, Biotek, Swindon, UK) at $450 \mathrm{~nm}$. Cell viability, determined by trypan blue exclusion test, was higher than $90 \%$ after both 24 and $96 \mathrm{~h}$ of incubation.

\section{Determination of Cytokines in Culture Supernatants by ELISA}

The assays were optimized in our laboratory for concentrations of mouse monoclonal antibodies (mAb), supernatants, polyclonal detecting antibody $(\mathbf{A b})$ and secondary conjugate Ab. The levels of IL-6 and IL-1 $\beta$ in cell-free supernatants were determined by capture ELISA performed in 96-well microtiter plates, according to Caroprese et al. (2006) with some modifications. Mouse $\mathrm{mAb}$ specific for ovine IL- 6 and for ovine IL-1 $\beta$ (Clone 4B6 for IL- 6 and Clone 1D4, Serotec Ltd., Killington, UK) dissolved in buffer carbonate ( $\mathrm{pH}$ 9.6) were used to coat wells, and plates were incubated overnight at $4^{\circ} \mathrm{C}$. After washing with PBS and $0.05 \%$ Tween 20 (PBST) the plates were incubated with blocking solution (PBST $/ 3 \%$ BSA) to block nonspecific binding. The supernatants were added and incubated, PBST provided negative control wells. Rabbit polyclonal antiovine IL-6 and IL-1 $\beta$ Ab (Serotec Ltd.) were used as detecting antibodies. The presence of IL- 6 and IL-1 $\beta$ binding was detected using sheep anti-rabbit IgG conju- 
gated to horseradish peroxidase (Sigma Aldrich), with the addition of $100 \mu \mathrm{L}$ of $3,3^{\prime}, 5,5^{\prime}$-tetramethylbenzidine substrate solution to each well for $30 \mathrm{~min}$. To stop the colorimetric reaction $50 \mu \mathrm{L}$ of $\mathrm{H}_{2} \mathrm{SO}_{4}(2 M)$ was added to each well. Optical density was measured at a wavelength of $450 \mathrm{~nm}$. All the incubations were at $37^{\circ} \mathrm{C}$ for 1 $\mathrm{h}$, and after each step, the plates were washed 4 times. Culture supernatants were read against a standard curve obtained using scalar dilution of recombinant ovine IL-6 (Cusabio Biotech Co., Wuhan, P.R. China) and recombinant bovine IL-1 $\beta$ (Kingfisher Biotech Inc., St. Paul, MN). Data are expressed in nanograms of IL- 6 and IL-1 $\beta$ per milliliter.

The concentration of IL-10 in supernatants was assayed by ELISA as follows: 96-well plates (Sterilin, Newport, UK) were coated overnight at $4^{\circ} \mathrm{C}$ with 100 $\mu \mathrm{L}$ of anti-bovine IL-10 mAb (Clone CC318, Serotec Ltd.; $2 \mu \mathrm{g} / \mathrm{mL}$ ) in buffer carbonate (pH 9.6). To block
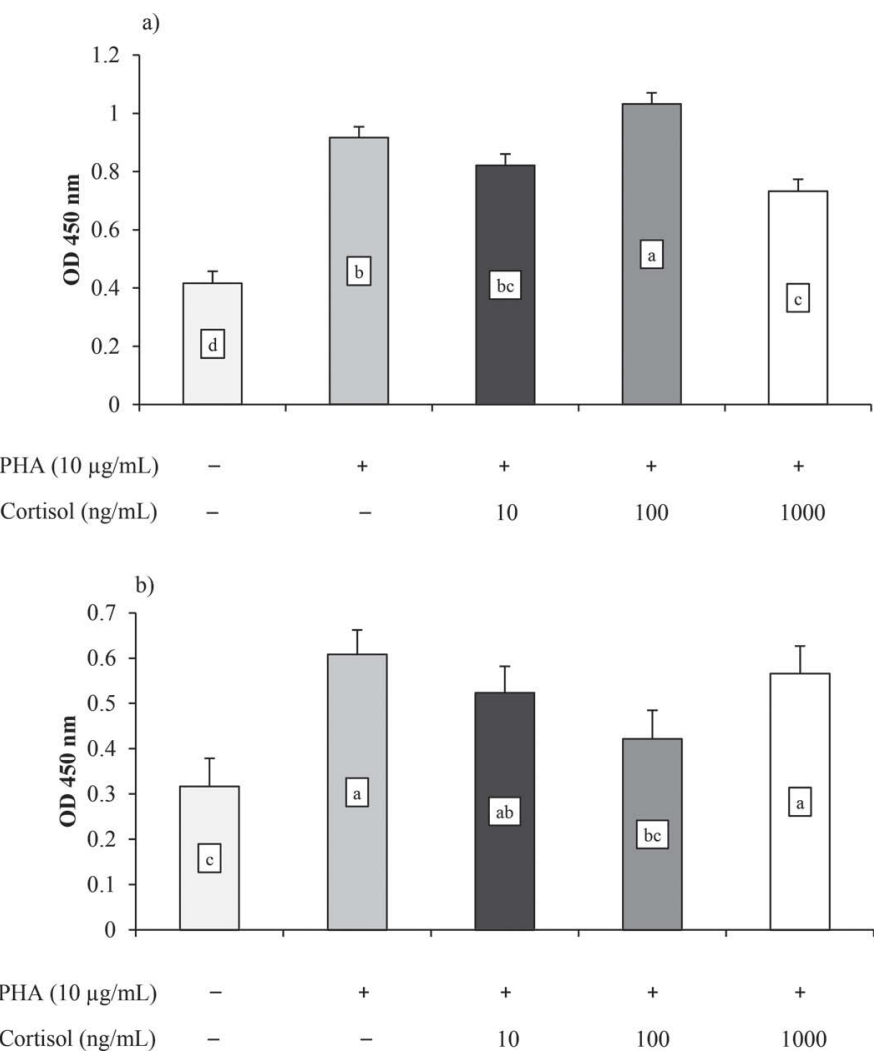

Figure 1. Proliferation of sheep peripheral blood mononuclear cells [PBMC, measured as optical density (OD) at $450 \mathrm{~nm}$; LSM \pm SEM] following in vitro stimulation. The PBMC were treated with incremental concentrations of cortisol $[10 \mathrm{ng} / \mathrm{mL}$ as basal cortisol concentration, $100 \mathrm{ng} / \mathrm{mL}$ as physiological poststressor concentration, and 1,000 $\mathrm{ng} / \mathrm{mL}$ as hyperactivated hypothalamic-pituitary-adrenal (HPA) axis concentration] and phytohemagglutinin (PHA, $10 \mu \mathrm{g} / \mathrm{mL}$ final concentration) and cultured for a) $24 \mathrm{~h}$ (acute stress), and b) $96 \mathrm{~h}$ (chronic stress). Different letters (a-d) indicate significant difference between treatment groups, $P<0.05$. nonspecific binding, PBST $/ 3 \%$ BSA was added for $1 \mathrm{~h}$. The IL-10 standard and samples were added to plate for $1 \mathrm{~h}$. Biotinylated secondary anti-bovine IL-10 mAb (Clone CC320 for IL-10, Serotec Ltd.) was added, after dilution in PBST $/ 1 \%$ BSA $(2 \mu \mathrm{g} / \mathrm{mL})$, and incubated for $1 \mathrm{~h}$. Subsequently, streptavidin-horseradish peroxidase (1/500 in PBS, Serotec Ltd.) was added for 45 min. Finally, 3,3',5,5'-tetramethylbenzidine substrate solution was added to each well for $30 \mathrm{~min}$, and the $\mathrm{H}_{2} \mathrm{SO}_{4}(2 M)$ was used to stop the colorimetric reaction. All incubations were performed at room temperature, and the plate was washed (4 times) after each step. The levels of IL-10 were measured colorimetrically at $450 \mathrm{~nm}$ (by subtracting absorbance at $540 \mathrm{~nm}$ ) and quantified by interpolation from standard curve. Data are expressed in nanograms of IL-10 per milliliter.

\section{Statistical Analysis}

All variables were tested for normality using the Shapiro-Wilk test (Shapiro and Wilk, 1965). All the data were analyzed using ANOVA for mixed models using the MIXED procedure of SAS (SAS Institute, 2013), with the cortisol concentrations, incubation times, and their interactions as fixed effects and the animal as a random factor nested in the treatment. Linear simple correlations between cytokine concentrations according to the cortisol concentrations and incubation times were investigated using PROC CORR of SAS. When significant effects were found $(P<0.05)$, the Fisher's Least Significant Difference test was used to locate significant differences between means.

\section{RESULTS}

\section{Proliferation of PBMC}

Cortisol concentrations affected cell proliferation (Figure 1a,b). After an acute stressor (i.e., after $24 \mathrm{~h}$ of incubation), the physiological poststressor concentration of cortisol $(100 \mathrm{ng} / \mathrm{mL})$ increased PBMC proliferation compared with stimulated cells $(P<0.001)$; whereas, hyperactivated HPA axis concentration of cortisol $(1,000 \mathrm{ng} / \mathrm{mL})$ decreased PBMC proliferation compared with stimulated cells $(P<0.001)$. After chronic stress (i.e., after $96 \mathrm{~h}$ of incubation), the physiological poststressor concentration of cortisol inhibited PBMC proliferation compared with stimulated cells.

Increased incubation time was associated with a significant decrease in PBMC proliferation $(P<0.001)$; in particular, PBMC proliferation decreased after chronic stress compared with acute stress in PHA-stimulated PBMC and in PHA-stimulated PBMC cultured with the basal concentration of cortisol $(10 \mathrm{ng} / \mathrm{mL})$ and the 
physiological poststressor concentration of cortisol $(P$ $<0.001)$.

\section{Cytokine Production by PBMC}

Cortisol concentrations affected the amount of IL-6 produced by PBMC after both acute and chronic stress $(P<0.05$ and $P<0.001$, respectively). After acute stress, the amount of IL-6 from PBMC cultured with physiological poststressor concentration of cortisol decreased compared with that produced by PHA-stimulated PBMC (Figure 2a). In contrast, after chronic stress PBMC cultured with a physiological poststressor concentration of cortisol overproduced IL-6 in comparison with PHA-stimulated PBMC (Figure 2 b). A significant increase of IL-6 production by PBMC was found when passing from acute to chronic stress $(P<$ 0.001); in particular, the production of IL- 6 by PBMC cultured with a physiological poststressor concentration of cortisol was the highest after chronic stress $(P<$ $0.001)$.

The concentration of IL-1 $\beta$ after acute stress was affected by cortisol concentrations $(P<0.01)$; physiological poststressor and hyperactivated HPA axis concentrations of cortisol decreased IL- $1 \beta$ produced by PBMC compared with unstimulated cells (Figure 3a). The interaction of cortisol concentrations and incubation time affected the IL- $1 \beta$ concentration, which was higher after chronic stress compared with acute stress $(P<0.001)$. In particular, cells treated with the physiological poststressor concentration of cortisol produced higher levels of IL-1 $\beta$ after chronic stress compared with acute stress $(8.2 \pm 1.1$ vs. $4.6 \pm 0.8 \mathrm{ng} / \mathrm{mL}, P<0.05)$.

The production of IL-10 was affected by cortisol concentrations $(P<0.05)$, incubation time $(P<0.001)$, and their interaction $(P<0.05)$. The hyperactivated HPA axis concentration of cortisol increased IL-10 production by PBMC after acute stress compared with PHA-stimulated PBMC (Figure 4 a); an opposite effect was registered after chronic stress (Figure $4 \mathrm{~b}$ ). The production of IL-10 was higher after chronic stress than after acute stress in both PHA-stimulated PBMC and PBMC cultured with physiological poststressor concentration of cortisol.

A positive correlation between IL- 6 and IL-10 concentrations was found when PBMC were cultured with physiological poststressor concentration of cortisol during chronic stress $(\mathrm{r}=0.55, P<0.01)$.

\section{DISCUSSION}

Glucocorticoids are widely used to suppress inflammation, and their effects on inflammatory processes have been investigated in depth (Dhabhar, 2014; Frank et al., 2010, 2013). They have an important role in coordinating the magnitude and duration of host immune responses (Zhang and Daynes, 2007). The permissive or suppressive effects of Gc on the immune system depend on various key factors, such as their concentration, leukocyte redistribution, and the duration of stress (Dhabhar, 2014).

Depending on the immune activation conditions and the nature of the activating agent, acute stress has been shown to significantly enhance the innate and adaptive primary and secondary immune responses. In human and animal studies, chronic stress has been shown to suppress different immune parameters, examples of which include antibody production, natural killer activity, and leukocyte proliferation (Dhabhar, 2014). The inhibition of cell growth can be attributed to reduced expression of major histocompatibility complex class II proteins (Sapolsky et al., 2000). The hypothesis that acute stress enhances immune functions, whereas

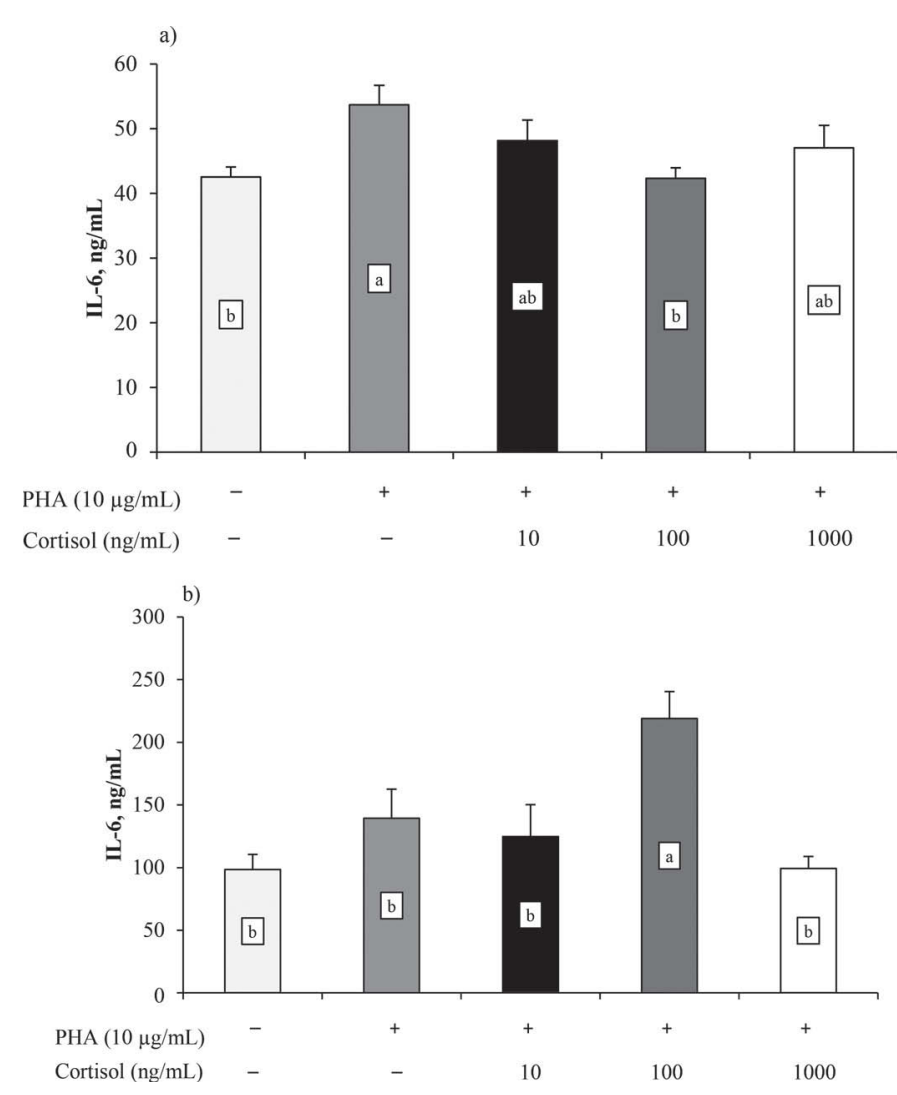

Figure 2. Interleukin-6 secretion (LSM \pm SEM) by peripheral blood mononuclear cells (PBMC) following in vitro stimulation. The PBMC were treated with incremental concentration of cortisol [10 $\mathrm{ng} / \mathrm{mL}$ as basal cortisol concentration, $100 \mathrm{ng} / \mathrm{mL}$ as physiological poststressor concentration, and $1,000 \mathrm{ng} / \mathrm{mL}$ as hyperactivated hypothalamic-pituitary-adrenal (HPA) axis concentration] and phytohemagglutinin (PHA, $10 \mu \mathrm{g} / \mathrm{mL}$ final concentration) and cultured for a) $24 \mathrm{~h}$ (acute stress), and b) $96 \mathrm{~h}$ (chronic stress). Different letters (a, b) indicate significant difference between treatment groups, $P<0.05$. 
chronic stress suppresses or dysregulates immune function (Dhabhar et al., 1994, 1995; Dhabhar and McEwen, 1996), has been confirmed in sheep by our results on PBMC proliferation, particularly in cells treated with the physiological poststressor cortisol concentration. A previous study in rats (Wiegers et al., 1995) demonstrated that Gc are potent enhancers of antiT-cell receptor-induced lymphocyte proliferation of cells cultured for 2 to $3 \mathrm{~d}$ and inhibitors of cell growth of cells cultured for 5 to $7 \mathrm{~d}$. Accordingly, our data showed that when chronic stress occurs, physiological poststressor cortisol concentrations are responsible for the reduction of cell proliferation.

The Gc mechanisms of action on inflammatory processes include an increase in the expression of inflammatory cytokine receptors by immune effector cells, including receptors for IL- 1 and IL-6, and the subse-
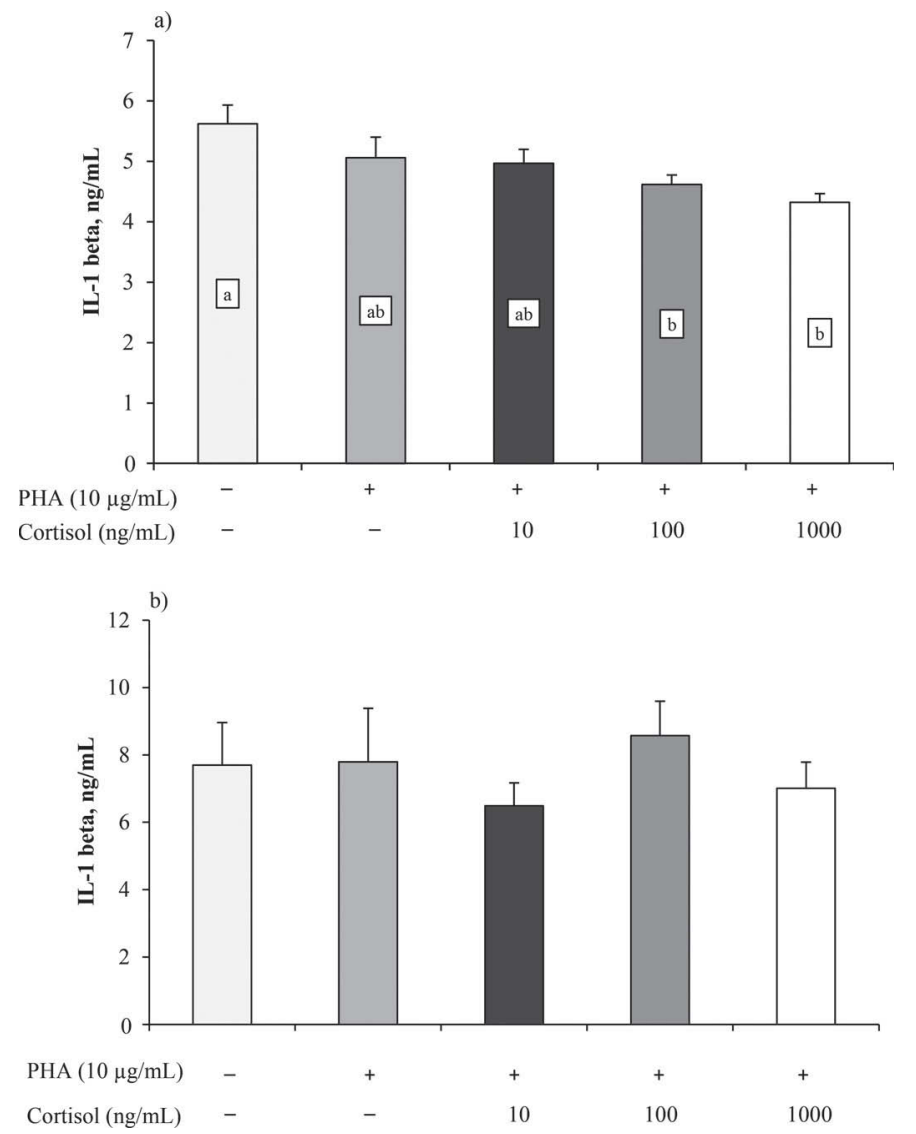

Figure 3. Interleukin-1 $\beta$ secretion by peripheral blood mononuclear cells $(\mathrm{PBMC})(\mathrm{LSM} \pm \mathrm{SEM})$ following in vitro stimulation. The PBMC were treated with incremental concentration of cortisol $[10 \mathrm{ng} / \mathrm{mL}$ as basal cortisol concentration, $100 \mathrm{ng} / \mathrm{mL}$ as physiological poststressor concentration, and $1,000 \mathrm{ng} / \mathrm{mL}$ as hyperactivated hypothalamic-pituitary-adrenal (HPA) axis concentration], and phytohemagglutinin (PHA, $10 \mu \mathrm{g} / \mathrm{mL}$ final concentration) and cultured for a) $24 \mathrm{~h}$ (acute stress), and b) $96 \mathrm{~h}$ (chronic stress). Different letters (a, b) indicate significant difference between treatment groups, $P<0.05$.
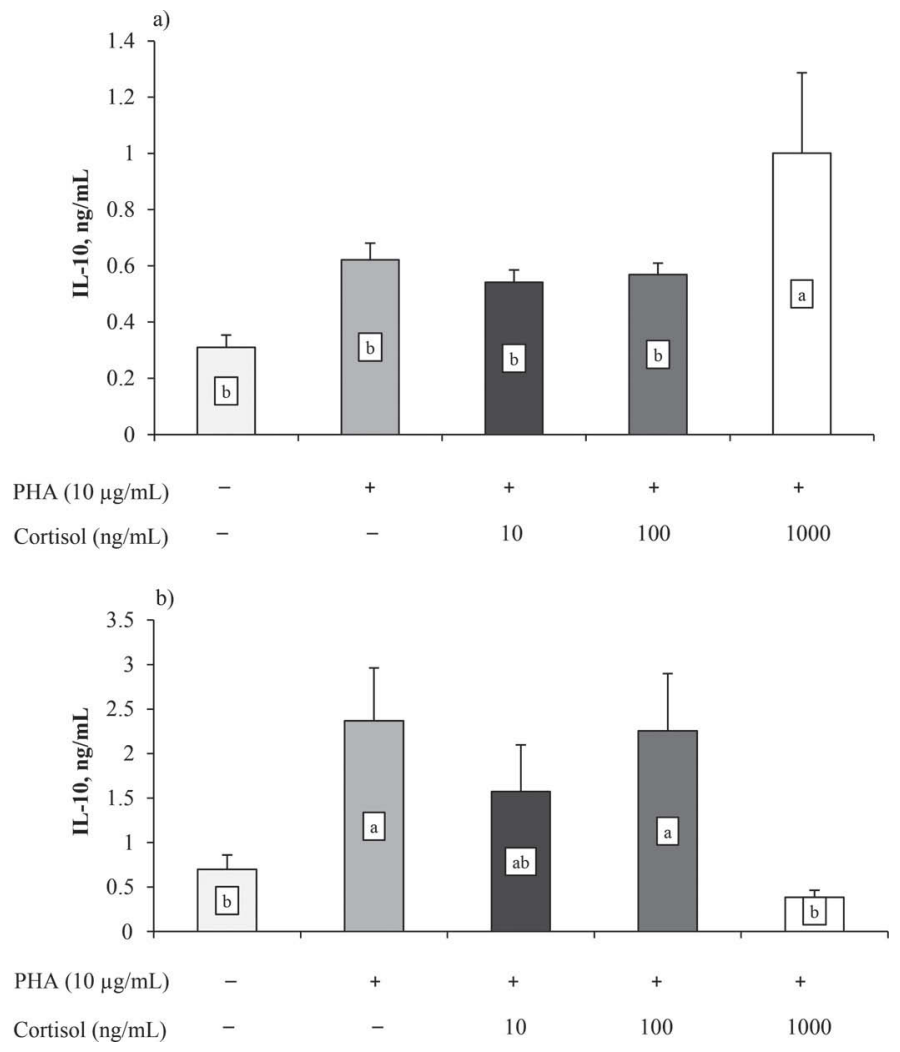

Figure 4. Interleukin-10 secretion by peripheral blood mononuclear cells (PBMC) (LSM \pm SEM) following in vitro stimulation. The PBMC were treated with incremental concentration of cortisol $[10 \mathrm{ng} / \mathrm{mL}$ as basal cortisol concentration, $100 \mathrm{ng} / \mathrm{mL}$ as physiological poststressor concentration, and $1,000 \mathrm{ng} / \mathrm{mL}$ as hyperactivated hypothalamic-pituitary-adrenal (HPA) axis concentration], and phytohemagglutinin (PHA, $10 \mu \mathrm{g} / \mathrm{mL}$ final concentration) and cultured for a) $24 \mathrm{~h}$ (acute stress), and b) $96 \mathrm{~h}$ (chronic stress). Different letters (a, b) indicate significant difference between treatment groups, $P<0.05$.

quent increase in endogenous release of IL-6 (Yeager et al., 2009). Several studies also showed that Gc increase the inflammatory response after LPS challenge, including the production of IL-1 $\beta$ (Dinkel et al., 2003). In our study, sheep PBMC cultured with physiological poststressor cortisol concentrations showed proinflammatory behavior, as demonstrated by an increase in IL-6 production and, to a lesser extent, IL-1 $\beta$ production after chronic stress. In contrast, after acute stress, PBMC cultured with the same cortisol concentrations showed a decrease in IL-6 but not in IL-1 $\beta$ production. Data demonstrated an evident shift in IL-6 production based on different duration of stress in sheep. Results also showed that IL-1 $\beta$ production was less responsive to magnitude of stress, with it being affected only by duration of stress when cells were cultured with physiological cortisol levels. Accordingly, in a previous study, a relation between in vivo plasma IL-6 levels and chronic stress during the transition period in sheep was found; 
however, IL-1 $\beta$ was less sensitive to transition period stress (Caroprese et al., 2006). In a recent review, IL-6 was described in relation to its hormone-like attributes and its ability to control homeostatic processes; moreover, a context-dependent role as a pro-inflammatory or anti-inflammatory cytokine was attributed to IL-6 (Hunter and Jones, 2015). Thus, early IL-6 production can promote inflammatory processes, while in a subsequent phase IL-6 can limit inflammation by promoting IL-10 production by T cells (Hunter and Jones, 2015; Stumhofer et al., 2007; McGeachy et al., 2007). Previous statements can help to explain the inverse relation between IL-6 production and PBMC proliferation after acute stress that was found in our study. Proliferation of PBMC appeared to be controlled and regulated by cross-talk between IL- 6 and IL-10 as demonstrated by the positive correlation found between IL- 6 and IL-10. In particular, IL-10 seemed to have a pivotal role in modulating cell proliferation and in mitigating the inflammatory conditions as demonstrated by cells incubated with physiological levels of cortisol after chronic stress. Although IL-10 shows potent anti-inflammatory/immunosuppressive properties in vitro (Rousset et al., 1992), it has been demonstrated to stimulate Bcell functions, suggesting both immunosuppressive and immunostimulatory effects on adaptive immune cell mediators (Mocellin et al., 2004). From a physiological point of view, IL-10 plays an important role in mitigating the inflammatory phenomena and establishing an equilibrium between protection from pathogen invasion and the possibility of tissue damage (Mocellin et al., 2004). Furthermore, Gc have a direct effect on IL-10 production because they are able to up-regulate IL10 secretion by $\mathrm{T}$ cells (Elenkov and Chrousos 1999). Guyre et al. (2008) reported that high levels of Gc can augment IL-10 secretion in a dose-dependent manner and in a time-dependent way in relation to the inflammatory stimulus. The role of IL-10 in controlling cell proliferation was confirmed by the results obtained by cells incubated with hyperactivated HPA axis concentrations of cortisol after acute stress. This finding supported the previously reported suppressive action exerted by Gc increase on immune responses (Dhabhar, 2014). In a previous study in heat-stressed ewes, the increase in cortisol secretion was responsible for an impaired cellular immune response after intradermal injection of mitogens (Sevi et al., 2002). Results from the present experiment lead to the hypothesis that Gc in sheep during acute stress have a dose-dependent effect on cell proliferation. Thus, according to previous statements, both the duration of stress (i.e., acute vs. chronic stress) and the intensity of stress (i.e., the concentrations of Gc) can be responsible for permissive or suppressive effects exerted by Gc on immune cells.

\section{CONCLUSIONS}

Glucocorticoids have been considered immunosuppressive and anti-inflammatory molecules, and an additional permissive mechanism of Gc on the immune system has recently been suggested. We showed that the bidirectional effect of cortisol on the immune system in sheep is related to the magnitude of the stressor and the duration of the stress. Physiological poststressor levels of cortisol negatively affected the levels of IL-6 secreted by PBMC and resulted in an increase in cell proliferation after acute stress. The same cortisol concentration exerted opposite effects under chronic stress conditions, resulting in a reduction in cell proliferation induced by increased levels of IL- 6 and strengthened by the coordinated action of IL- 6 and IL-10. Finally, hyperactivated HPA axis concentrations of cortisol resulted in a reduction of cell proliferation induced by the increase in IL-10 after acute stress. Data also showed that IL-6 is responsive to changes in the duration of stress in sheep. Our findings suggest that physiological levels of cortisol after a stressor can exert both immunostimulatory and immunosuppressive effects in vitro depending on the duration of stress. In contrast, levels of cortisol higher than physiological levels exert immunosuppressive effects after an acute stress.

\section{REFERENCES}

Caroprese, M., M. Albenzio, G. Annicchiarico, and A. Sevi. 2006. Changes occurring in immune responsiveness of single- and twin bearing Comisana ewes during the transition period. J. Dairy Sci. 89:562-568.

Caroprese, M., M. Albenzio, A. Marzano, L. Schena, G. Annicchiarico, and A. Sevi. 2010. Relationship between cortisol response to stress and behavior, immune profile, and production performance of dairy ewes. J. Dairy Sci. 93:2395-2403.

De Bosscher, K., W. V. Berghe, and G. Haegeman. 2003. The interplay between the glucocorticoid receptor and nuclear factor- $\kappa \mathrm{B}$ or activator protein-1: Molecular mechanisms for gene repression. Endocr. Rev. 24:488-522.

Dhabhar, F. S. 2002. Stress-induced augmentation of immune function-The role of stress hormones, leukocyte trafficking and cytokines. Brain Behav. Immun. 16:785-798.

Dhabhar, F. S. 2014. Effects of stress on immune function: The good, the bad, and the beautiful. Immunol. Res. 58:193-210.

Dhabhar, F. S., and B. S. McEwen. 1996. Stress-induced enhancement of antigen-specific cell mediated immunity. J. Immunol. 156:26082615.

Dhabhar, F. S., and B. S. McEwen. 1997. Acute stress enhances while chronic stress suppresses immune function in vivo: A potential role for leukocyte trafficking. Brain Behav. Immun. 11:286-306.

Dhabhar, F. S., A. H. Miller, B. S. McEwen, and R. L. Spencer. 1995. Effects of stress on immune cell distribution. Dynamics and hormonal mechanisms. J. Immunol. 154:5511-5527.

Dhabhar, F. S., A. H. Miller, M. Stein, B. S. McEwen, and R. L. Spencer. 1994. Diurnal and stress-induced change in distribution of peripheral blood leukocyte subpopulations. Brain Behav. Immun. 8:66-79

Dinkel, K., A. MacPherson, and R. M. Sapolsky. 2003. Novel glucocorticoid effect on acute inflammation in the CNC. J. Neurochem. 84:705-716. 
Elenkov, I. J., and G. P. Chrousos. 1999. Stress hormones, Th1/Th2 patterns, pro/anti-inflammatory cytokines and susceptibility to disease. Trends Endocrinol. Metab 10:359-368.

European Union. 2010. EU Directive 2010/63/EU of 22 September 2010 on the protection of animals used for scientific purposes. Off. J. L276:33-79.

Franchimont, D., J. Galon, M. S. Vacchio, S. Fan, R. Visconti, D. M. Frucht, V. Geenen, G. P. Chrousos, J. D. Ashwell, and J. J. O'Shea. 2002. Positive effects of glucocorticoids on T cell function by up-regulation of IL-7 receptor $\alpha$. J. Immunol. 168:2212-2218.

Frank, M. G., Z. D. Miguel, L. R. Watkins, and S. F. Maier. 2010 Prior exposure to glucocorticoids sensitizes the neuroinflammatory and peripheral inflammatory responses to $E$. coli lipopolysaccharide. Brain Behav. Immun. 24:19-30.

Frank, M. G., L. R. Watkins, and S. F. Maier. 2013. Stress-induced glucocorticoids as neuroendocrine alarm signal of danger. Brain Behav. Immun. 33:1-6.

Guyre, P., M. Yeager, and A. Munck. 2008. Glucocorticoid effects on immune responses. NeuroImmune Biol. 7:147-168.

Hawrylowicz, C. M., L. Guida, and E. Paleolog. 1994. Dexamethasone up-regulates granulocyte-macrophage colony-stimulating factor receptor expression on human monocytes. Immunology 83:274-280.

Hunter, C. A., and S. A. Jones. 2015. IL-6 as a keystone cytokine in health and disease. Nat. Immunol. 16:448-457.

McGeachy, M. J., K. S. Bak-Jensen, Y. Chen, and D. J. Cua. 2007. TGF- $\beta$ and IL- 6 drive the production of IL-17 and IL-10 by T cells and restrain Th-17 cell-mediated pathology. Nat. Immunol. 8:1390-1397.

Mocellin, S., F. Marincola, C. R. Rossi, D. Nitti, and M. Lise. 2004 The multifaceted relationship between IL-10 and adaptive immunity: Putting together the pieces of a puzzle. Cytokine Growth Factor Rev. 15:61-76.

Munck, A., P. M. Guyre, and N. J. Holbrook. 1984. Physiological functions of glucocorticoids in stress and their relation to pharmacological actions. Endocr. Rev. 5:25-44.

Paterson, R. L., R. Or, J. M. Domenico, G. Delespesse, and E. W. Gelfand. 1994. Regulation of CD23 expression by IL-4 and corticosteroid in human B lymphocytes. J. Immunol. 152:2139-2147.

Pietzko, D., D. Zohlnhofer, L. Graeve, D. Fleischer, T. Stoyan, H. Schooltink, S. R. John, and P. C. Heinrich. 1993. The hepatic interleukin-6 receptor. J. Biol. Chem. 268:4250-4258.

Rousset, F., E. Garcia, T. Defrance, C. Perrone, N. Vezzio, D. H. Hsu, R. Kastelein, K. W. Moore, and J. Banchereau. 1992. Interleukin
10 is a potent growth and differentiation factor for activated human B lymphocytes. Proc. Natl. Acad. Sci. USA 89:1890-1893.

Sapolsky, R. M., M. Romero, and A. U. Munck. 2000. How do glucocorticoids influence stress responses? Integrating permissive, suppressive, stimulatory, and preparative actions. Endocr. Rev. 21:55-89.

SAS Institute. 2013. SAS Enterprise Guide: Statistics. Version 6.1. SAS Inst. Inc., Cary, NC.

Sevi, A., M. Albenzio, G. Annicchiarico, M. Caroprese, R. Marino, and L. Taibi. 2002. Effects of ventilation regimen on the welfare and performance of lactating ewes in summer. J. Anim. Sci. 80:2349 2361

Shapiro, S. S., and M. B. Wilk. 1965. An analysis of variance test for normality. Biometrika 52:591-601.

Shieh, J. H., R. H. Peterson, and M. A. Moore. 1993. Cytokines and dexamethasone modulation of IL-1 receptors on human neutrophils in vitro. J. Immunol. 150:3515-3524.

Strickland, R. W., L. M. Wahl, and D. S. Finblood. 1986. Corticoid steroids enhance the binding of recombinant interferon- $\mathrm{V}$ to cultured human monocytes. J. Immunol. 137:1577-1580.

Stumhofer, J. S., J. S. Silver, A. Laurence, P. M. Porrett, T. H. Harris, L. A. Turka, M. Ernst, C. J. Saris, J. J. O'Shea, and C. A. Hunter 2007. Interleukin 27 and 6 induce STAT3-mediated T cell production of interleukin 10. Nat. Immunol. 8:1363-1371.

Wattegedera, S., K. Sills, C. J. Howard, J. C. Hope, C. J. McInnes, and G. Entrican. 2004. Variability in cytokine production and cell proliferation by mitogen-activate ovine peripheral blood mononuclear cells: Modulation by interleukin (IL)-10 and IL-12. Vet. Immunol. Immunopathol. 102:67-76.

Wiegers, G. J., M. Labeur, I. Stec, W. E. F. Klinkert, F. Holsboer, and J. M. H. M. Reul. 1995. Glucocorticoids accelerate anti-T cell receptor induced T cell growth. J. Immunol. 155:1893-1902.

Yeager, M. P., A. J. Rassias, P. A. Pioli, M. L. Beach, K. Wardwell, J. E. Collins, H. K. Lee, and P. M. Guyre. 2009. Pretreatment with stress cortisol enhances the human systemic inflammatory response to bacterial endotoxin. Crit. Care Med. 37:2727-2732.

Zhang, T. Y., and R. A. Daynes. 2007. Glucocorticoid conditioning of myeloid progenitors enhances TRL4 signaling via negative regulation of the phosphatidylinositol 3-kinase-Akt pathway. J. Immunol. 178:2517-2526. 